\title{
Silver Orthophosphate Immobilized on Flaky Layered Double Hydroxides as the Visible-Light-Driven Photocatalysts
}

\author{
Xianlu Cui, ${ }^{1}$ Yaogang Li, ${ }^{2}$ Qinghong Zhang, ${ }^{2}$ and Hongzhi Wang1 \\ ${ }^{1}$ State Key Laboratory for Modification of Chemical Fibers and Polymer Materials, Donghua University, Shanghai 201620, China \\ ${ }^{2}$ Engineering Research Center of Advanced Glasses Manufacturing Technology, MOE, Donghua University, Shanghai 201620, China
}

Correspondence should be addressed to Qinghong Zhang, zhangqh@dhu.edu.cn and Hongzhi Wang, wanghz@dhu.edu.cn

Received 15 July 2011; Accepted 19 September 2011

Academic Editor: Jinlong Zhang

Copyright ( $) 2012$ Xianlu Cui et al. This is an open access article distributed under the Creative Commons Attribution License, which permits unrestricted use, distribution, and reproduction in any medium, provided the original work is properly cited.

\begin{abstract}
Flaky layered double hydroxide (FLDH) was prepared by the reconstruction of its oxide in alkali solution. The composites with $\mathrm{FLDH} / \mathrm{Ag}_{3} \mathrm{PO}_{4}$ mass ratios at 1.6:1 and 3:1 were fabricated by the coprecipitation method. The powders were characterized by $\mathrm{X}$-ray diffraction, field-emission scanning electron microscopy, transmission electron microscope, and UV-vis diffuse reflectance spectroscopy. The results indicated that the well-distributed $\mathrm{Ag}_{3} \mathrm{PO}_{4}$ in a fine crystallite size was formed on the surface of FLDH. The photocatalytic activities of the $\mathrm{Ag}_{3} \mathrm{PO}_{4}$ immobilized on $\mathrm{FLDH}$ were significantly enhanced for the degradation of acid red $\mathrm{G}$ under visible light irradiation compared to bare $\mathrm{Ag}_{3} \mathrm{PO}_{4}$. The composite with the FLDH/ $\mathrm{Ag}_{3} \mathrm{PO}_{4}$ mass ratio of $3: 1$ showed a higher photocatalytic efficiency.
\end{abstract}

\section{Introduction}

The treatment of environmental pollutants in waste water by active semiconductor photocatalysts has recently attracted considerable attention for its ability to completely oxidize organic contaminants to carbon dioxide, water, and mineral acids [1-5]. Among the semiconductor photocatalysts, $\mathrm{TiO}_{2}$ has been extensively studied because of its outstanding photocatalytic activity, long-term stability, low cost, and nontoxicity $[6,7]$. However, $\mathrm{TiO}_{2}$ can only be activated with UV light with a wavelength of less than $385 \mathrm{~nm}$ due to its wide band gap $(\sim 3.2 \mathrm{eV})$, which limits its utilization of the solar energy. Therefore, a growing interest is also focused on the development of the new photocatalysts that can operate effectively under visible light irradiation. The doping of $\mathrm{TiO}_{2}$ with foreign elements such as metals and nonmetals to improve the energy band structure of $\mathrm{TiO}_{2}$ has been extensively investigated [8], and nitrogen doping $\mathrm{TiO}_{2}$ has been demonstrated as a visible light photocatalyst [9]. However, the absorption edge of $\mathrm{N}$-doped $\mathrm{TiO}_{2}$ was just extended to the wavelength below $450 \mathrm{~nm}$ with a lower absorption constant. The non- $\mathrm{TiO}_{2}$-based photocatalysts with a larger absorption coefficient, such as $\mathrm{Ta}_{3} \mathrm{~N}_{5}$ [10], $\mathrm{Ga}_{1-x} \mathrm{Zn}_{x} \mathrm{~N}_{1-x} \mathrm{O}_{x}$ $[11,12], \mathrm{BiVO}_{4}[13,14], \mathrm{Bi}_{2} \mathrm{WO}_{6}[15,16]$, and $\mathrm{Ag}_{2} \mathrm{CrO}_{4}$
[17] have also been studied during the past decade. Up to now, the development of novel visible-light-responsive photocatalysts with expanded spectral response range and high photocatalysis quantum efficiency is still necessary.

Recently, Yi et al. reported the new use of $\mathrm{Ag}_{3} \mathrm{PO}_{4}$ semiconductor as a visible light photocatalyst, which can oxidize water as well as decompose organic contaminants in aqueous solution [18]. It was found that it exhibited extremely high photocatalytic efficiency for organic dye decomposition under visible light irradiation and the decomposition of methylene blue over $\mathrm{Ag}_{3} \mathrm{PO}_{4}$ was dozens of times quicker than that over monoclinic $\mathrm{BiVO}_{4}$ and commercial $\mathrm{TiO}_{2-x} \mathrm{~N}_{x}$. However, the effect about reducing the crystallite size of $\mathrm{Ag}_{3} \mathrm{PO}_{4}$ on photocatalysis is still unknown.

Layered double hydroxide (LDH), also called hydrotalcite-like compound or anionic clay, is a family of lamellar ionic solids that in terms of layer charge are the counterpart of cationic clay minerals [19]. The LDH has a unique property known as "memory effect," which refers to that $\mathrm{LDH}$ is decomposed into mixed metal oxide (MMO) when $\mathrm{LDH}$ calcined at $300-600^{\circ} \mathrm{C}$. The calcined $\mathrm{LDH}$ is able to recover the original layered structure easily when exposed to the air or put into anion aqueous solution $[4,20]$. In our previous work, we have prepared flaky layered double 
hydroxides (FLDH) composed of cross-linked nanoflakes by the reconstruction of their oxides in alkali solution, and the $\mathrm{ZnO}$ immobilized on FLDH generated highly dispersed $\mathrm{ZnO}$ nanoparticles $(\sim 9.5 \mathrm{~nm}$ in diameter) with an enhanced photocatalytic efficiency [21]. Nevertheless, the band gap of this composite $(\sim 3.18 \mathrm{eV})$ is too wide to absorb sunlight efficiently. In this work, we synthesized the $\mathrm{Ag}_{3} \mathrm{PO}_{4} / \mathrm{FLDH}$ composites, and the much finer $\mathrm{Ag}_{3} \mathrm{PO}_{4}$ was obtained in the presence of FLDH and the resulted composites exhibited a higher visible light photocatalytic efficiency compared to bare $\mathrm{Ag}_{3} \mathrm{PO}_{4}$.

\section{Experimental}

2.1. Synthesis of Materials. The Mg-Al- $\mathrm{CO}_{3} \mathrm{LDH}$ was prepared by coprecipitation by a high supersaturation method [22]. A typical preparation process was described as follows. Solution A was prepared by dissolving $\mathrm{AlCl}_{3} \cdot 6 \mathrm{H}_{2} \mathrm{O}$ $(62.5 \mathrm{mmoL})$ and $\mathrm{MgCl}_{2} \cdot 6 \mathrm{H}_{2} \mathrm{O}(125 \mathrm{mmoL})$ in $87.5 \mathrm{~mL}$ of deionized water and solution $\mathrm{B}$ prepared via dissolving $\mathrm{NaOH}(437 \mathrm{mmoL})$ and $\mathrm{Na}_{2} \mathrm{CO}_{3}(208 \mathrm{mmoL})$ in $125 \mathrm{~mL}$ of deionized water. Solution A was added to solution B in a three-neck round-bottom reaction flask and then stirred at $50^{\circ} \mathrm{C}$, subsequently heated to $90^{\circ} \mathrm{C}$ for $4 \mathrm{~h}$. $\mathrm{LDH}$ was obtained after collection of the precipitates by filtration, washing several times with distilled water, and drying at $90^{\circ} \mathrm{C}$ overnight.

FLDH was prepared by the reconstruction of its oxide in alkali solution [21]. Firstly, LDH was calcined in air at $500^{\circ} \mathrm{C}$ for $4 \mathrm{~h}$, with a heating rate of $4^{\circ} \mathrm{C} / \mathrm{min}$, to prepare the MMO. Secondly, $3.0 \mathrm{~g}$ MMO was dispersed into $200 \mathrm{~mL} 1.0 \mathrm{M}$ $\mathrm{Na}_{2} \mathrm{CO}_{3}$ solution and stirred for $5 \mathrm{~min}$; the suspension was then transferred into a temperature-humidity chamber and stirred for $24 \mathrm{~h}$ at $6^{\circ} \mathrm{C}$. FLDH was obtained after collection of the precipitates by filtration, washing several times with distilled water, and drying at $90^{\circ} \mathrm{C}$ overnight.

The $\mathrm{Ag}_{3} \mathrm{PO}_{4} / \mathrm{FLDH}$ composites were prepared as follows. $3.0 \mathrm{~g}$ FLDH mixed with $4.8 \mathrm{~g} \mathrm{Na}_{2} \mathrm{HPO}_{4}$ was placed into $150 \mathrm{~mL}$ of the distilled water under room temperature and stirred for $5 \mathrm{~min}$. A proper amount of $\mathrm{AgNO}_{3}$ was dissolved in $50 \mathrm{~mL}$ of the distilled water and added to the suspension above. After stirring vigorously for $20 \mathrm{~min}$ at room temperature, the suspension was filtered, washed several times with distilled water, and dried at $60^{\circ} \mathrm{C}$ overnight. By varying the amount of $\mathrm{AgNO}_{3}$, the composites with $\mathrm{Ag}_{3} \mathrm{PO}_{4} / \mathrm{FLDH}$ mass ratios at $1: 1.6$ and $1: 3$ (labeled $\mathrm{Ag}_{3} \mathrm{PO}_{4} / \mathrm{FLDH}-1.6$ and $\mathrm{Ag}_{3} \mathrm{PO}_{4} / \mathrm{FLDH}-3$, resp.) were prepared. Bare $\mathrm{Ag}_{3} \mathrm{PO}_{4}$ sample without FLDH was also prepared by a similar method.

2.2. Characterization. The X-ray diffraction (XRD) patterns of the powder phase compositions were identified by X-ray diffractometer (Model D/Max-2550, Rigaku Co., Japan) using $\mathrm{Cu} \mathrm{K}_{\alpha}$ irradiation $(\lambda=1.5406 \AA)$ at $40 \mathrm{kV}$ and $100 \mathrm{~mA}$. The size and morphology of the samples were determined by field emission scanning electron microscopy (FE-SEM) (Model S-4800, Hitachi, Japan) and transmission electron microscope (TEM) (Model JEM-2100F, JEOL, Japan). The Brunauer-Emmett-Teller (BET) specific surface area measurement and the Barrett-Joyner-Halenda $(\mathrm{BJH})$ pore volume were performed using a nitrogen adsorption apparatus (Model Autosorb-1MP, Quantachrome Instruments Co., USA). The UV-vis diffuse reflectance spectra of the powder samples were collected in the form of a dry-pressed disk at room temperature with a spectrophotometer (Model Lambda 950, Perkin-Elmer Co., USA).

2.3. Photocatalytic Tests. Photocatalytic activities of the resultant bare $\mathrm{Ag}_{3} \mathrm{PO}_{4}$ and $\mathrm{Ag}_{3} \mathrm{PO}_{4} / \mathrm{FLDH}$ composites were evaluated by the photocatalytic decomposition of acid red $\mathrm{G}$ (ARG) under visible light irradiation. A $500 \mathrm{~W}$ Xe lamp was used as the light source, and a ZJB 420 filter glass was used to cut off light of wavelength $<420 \mathrm{~nm}$. In view of the fact that $\mathrm{Ag}_{3} \mathrm{PO}_{4}$ was slightly soluble in aqueous solution [23], the amount of catalysts in every experiment was normalized by the mass of $\mathrm{Ag}_{3} \mathrm{PO}_{4}$ really present in each sample and made sure that the amount of $\mathrm{Ag}_{3} \mathrm{PO}_{4}$ in ARG solution equal to $1 \mathrm{~g} / \mathrm{L}$. The experiments were performed as follows. Amount of photocatalyst was added into $100 \mathrm{~mL}$ ARG $(50 \mathrm{mg} / \mathrm{L})$. The aqueous suspension was stirred at room temperature and irradiated with visible light. About $3 \mathrm{~mL}$ of reaction suspension was sucked at a defined time interval, and the solid material was separated by centrifugation. The removal rates of ARG were measured on a UV-vis spectrophotometer (Model Lambda 35, Perkin-Elmer Co., USA) at the wavelength of $530 \mathrm{~nm}$.

\section{Results and Discussion}

3.1. Characterization. Figure 1 shows the XRD patterns of the original LDH, MMO, and FLDH. The typical X-ray pattern of the original LDH (Figure 1(a)) exhibits the typical reflections of $\mathrm{Mg}-\mathrm{Al}-\mathrm{CO}_{3}-\mathrm{LDH}$ with a series of narrow, symmetric, and sharp peaks, indicating a high degree of crystallinity [24]. Calcination of the $\mathrm{LDH}$ at $500^{\circ} \mathrm{C}$ resulted in the formation of a mixed metal oxide phase with an $\mathrm{MgO}-$ like structure (Figure 1(b)). After regeneration by soaking the MMO into a $\mathrm{Na}_{2} \mathrm{CO}_{3}$ solution, the calcined $\mathrm{LDH}$ have successfully recovered the original layered structure according to the characteristic reflections corresponding to the original LDH (Figure 1(c)), though a loss of some degree of crystallinity as reported elsewhere [25].

The XRD patterns of bare $\mathrm{Ag}_{3} \mathrm{PO}_{4}, \mathrm{Ag}_{3} \mathrm{PO}_{4} / \mathrm{FLDH}-1.6$, and $\mathrm{Ag}_{3} \mathrm{PO}_{4} / \mathrm{FLDH}-3$ are shown in Figure 2. For bare $\mathrm{Ag}_{3} \mathrm{PO}_{4}$ (Figure 2(a)), all of the diffraction peaks are well indexed as the body-centered cubic $\mathrm{Ag}_{3} \mathrm{PO}_{4}$ (JCPDS No. 060505). For the $\mathrm{Ag}_{3} \mathrm{PO}_{4} / \mathrm{FLDH}$ composites (Figures 2(b) and $2(\mathrm{c})$ ), most of the diffraction peaks could be attributed to the body-centered cubic $\mathrm{Ag}_{3} \mathrm{PO}_{4}$. Meanwhile, small diffraction peaks of LDH have been detected just as that in Figure 1(c), confirming that the FLDH preserve its original structure after being coated with $\mathrm{Ag}_{3} \mathrm{PO}_{4}$.

The FE-SEM images in Figure 3 show the morphologies of LDH and FLDH. Figure 3(a) shows the plate-like morphology typical of LDH [26] with diameters in the range 50$100 \mathrm{~nm}$. After regeneration, as shown in Figure 3(b), FLDH is made up of flaky sheets coalesced irregularly with each other. 


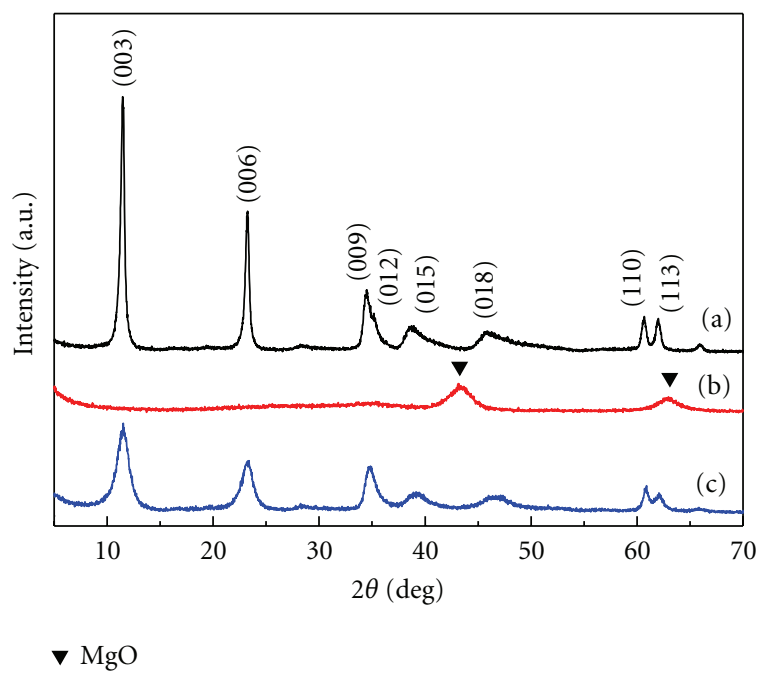

FIGURE 1: XRD patterns of (a) the original LDH, (b) MMO, and (c) FLDH.

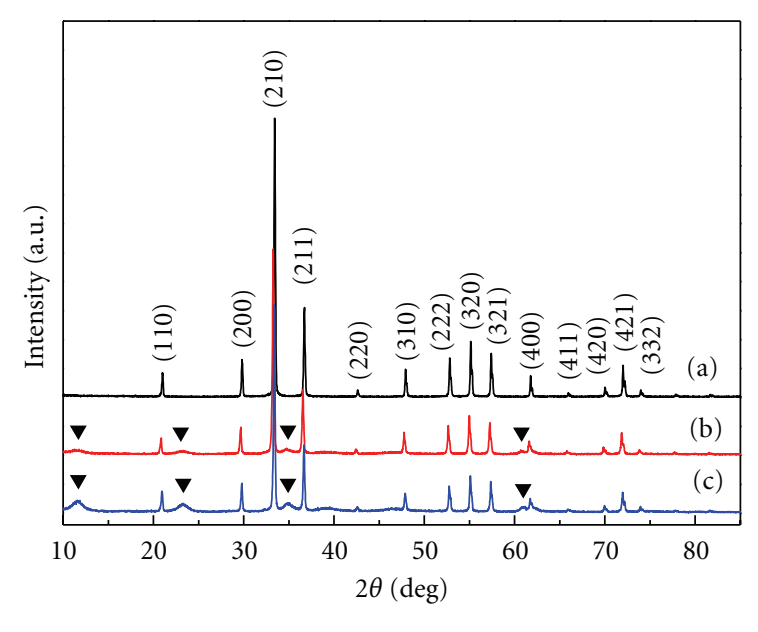

$\nabla \mathrm{LDH}$

FIGURE 2: XRD patterns of (a) bare $\mathrm{Ag}_{3} \mathrm{PO}_{4}$, (b) $\mathrm{Ag}_{3} \mathrm{PO}_{4} / \mathrm{FLDH}-1.6$, and (c) $\mathrm{Ag}_{3} \mathrm{PO}_{4} / \mathrm{FLDH}-3$.

The sizes of the flaky sheets range from 50 to $200 \mathrm{~nm}$, and the thickness is $\sim 10 \mathrm{~nm}$. It means that these sheets have a large aspect ratio (defined as platelet diameter/thickness) which may lead to an efficient adsorption capability.

The TEM images in Figure 4 show the sizes and morphologies of $\mathrm{Ag}_{3} \mathrm{PO}_{4}$ and $\mathrm{Ag}_{3} \mathrm{PO}_{4} / \mathrm{FLDH}-3$. The TEM image of bare $\mathrm{Ag}_{3} \mathrm{PO}_{4}$ shows agglomerated particles with diameters in the range $200-1000 \mathrm{~nm}$ (Figure 4(a)). The average diameter of the well-distributed $\mathrm{Ag}_{3} \mathrm{PO}_{4}$ in the $\mathrm{Ag}_{3} \mathrm{PO}_{4} / \mathrm{FLDH}-3$ composite $(\sim 200 \mathrm{~nm})$ is smaller than that of the bare $\mathrm{Ag}_{3} \mathrm{PO}_{4}$ (Figure 4(a)). From these results, it can be concluded that FLDH plays an important role in hindering the crystal growth and agglomeration of $\mathrm{Ag}_{3} \mathrm{PO}_{4}$. Figure 4(c) shows the energy dispersive spectroscopy (EDS) pattern of $\mathrm{Ag}_{3} \mathrm{PO}_{4} /$ FLDH-3. Except for the $\mathrm{Cu}$ and $\mathrm{C}$ peaks coming from the copper grid for the TEM analysis, the $\mathrm{Mg}$ and $\mathrm{Al}$ peaks are
TABLE 1: Corresponding specific surface area and pore volume for the samples.

\begin{tabular}{lcc}
\hline Sample & $S_{\mathrm{BET}}^{\mathrm{a}}\left(\mathrm{m}^{2} / \mathrm{g}\right)$ & $V^{\mathrm{b}}\left(\mathrm{cm}^{3} / \mathrm{g}\right)$ \\
\hline $\mathrm{LDH}$ & 110.4 & 0.336 \\
$\mathrm{FLDH}$ & 146.4 & 0.769 \\
$\mathrm{Ag}_{3} \mathrm{PO}_{4}$ & 1.6 & 0.002 \\
$\mathrm{Ag}_{3} \mathrm{PO}_{4} / \mathrm{FLDH}-1.6$ & 106.1 & 0.495 \\
$\mathrm{Ag}_{3} \mathrm{PO}_{4} / \mathrm{FLDH}-3$ & 122.3 & 0.601 \\
\hline
\end{tabular}

aBET surface area determined by a multipoint BET method, using the adsorption data in the relative pressure $(P / P 0)$ range $0.05-0.3 .{ }^{b} \mathrm{BJH}$ pore volume determined by the volume of nitrogen adsorbed at a relative pressure $(P / P 0)$ of 0.994 .

corresponding to $\mathrm{FLDH}$, and the presence of $\mathrm{Ag}$ and $\mathrm{P}$ elements indicates the formation of $\mathrm{Ag}_{3} \mathrm{PO}_{4}$. This result confirms that $\mathrm{Ag}_{3} \mathrm{PO}_{4} / \mathrm{FLDH}$ composites were successfully prepared in this study.

The BET specific surface area and pore volume of the samples are summarized in Table 1. It can be seen that the original LDH has a BET surface area $110.4 \mathrm{~m}^{2} / \mathrm{g}$ with a relative lower pore volume $0.336 \mathrm{~cm}^{3} / \mathrm{g}$. After regeneration, the BET specific surface area and pore volume of FLDH are much larger than that of LDH, this may be because the newly formed FLDH has a coarse surface due to the irregular interconnected nanosheets and the remaining slit-like mesopores as shown in Figure 3(b) [21]. This higher surface area and the special structure are considered to be a suitable support for $\mathrm{Ag}_{3} \mathrm{PO}_{4}$ dispersion. The surface area of $\mathrm{Ag}_{3} \mathrm{PO}_{4} / \mathrm{FLDH}-1.6$, and $\mathrm{Ag}_{3} \mathrm{PO}_{4} / \mathrm{FLDH}-3$ are slightly lower than that of FLDH and decrease with increasing the $\mathrm{Ag}_{3} \mathrm{PO}_{4} / \mathrm{FLDH}$ mass ratios. This could be attributed to that the presence of $\mathrm{Ag}_{3} \mathrm{PO}_{4}$ can clog the pore of FLDH, and this effect is more and more significant with the amount of $\mathrm{Ag}_{3} \mathrm{PO}_{4}$, which is further confirmed by change in the pore volume. It can also be observed that the surface area and pore volume of bare $\mathrm{Ag}_{3} \mathrm{PO}_{4}$ are very low, which is expected to be responsible for the subsequent poor adsorption capacity of ARG.

The UV-vis diffuse reflectance spectra of the bare $\mathrm{Ag}_{3} \mathrm{PO}_{4}$, $\mathrm{Ag}_{3} \mathrm{PO}_{4} / \mathrm{FLDH}-1.6$ and $\mathrm{Ag}_{3} \mathrm{PO}_{4} / \mathrm{FLDH}-3$ are shown in Figure 5. It can be clearly seen that the bare $\mathrm{Ag}_{3} \mathrm{PO}_{4}$ can absorb solar energy with a wavelength shorter than $\sim 530 \mathrm{~nm}$ as reported by Yi et al. [18]. As for $\mathrm{Ag}_{3} \mathrm{PO}_{4} / \mathrm{FLDH}$ composites, the absorption edge of each sample shifts to a slightly shorter wavelength compared with bare $\mathrm{Ag}_{3} \mathrm{PO}_{4}(\sim 525 \mathrm{~nm}$ for $\mathrm{Ag}_{3} \mathrm{PO}_{4} / \mathrm{FLDH}-1.6$ and $\sim 520 \mathrm{~nm}$ for $\mathrm{Ag}_{3} \mathrm{PO}_{4} / \mathrm{FLDH}-$ $3)$, though the absorption intensity slightly decreases. The decrease of absorption intensity is dependent on the content of $\mathrm{Ag}_{3} \mathrm{PO}_{4}$ in these composites.

3.2. Degradation of ARG Solution. The photocatalytic activity of $\mathrm{Ag}_{3} \mathrm{PO}_{4}$ may be explained by that $\mathrm{Ag}_{3} \mathrm{PO}_{4}$ has a large dispersion of conduction band due to the form of the delocalized $\pi^{*}$ antibonding states in the conduction band and the inductive effect of $\mathrm{PO}_{4}{ }^{3-}$, which helps the separation of electron-hole pairs [27], and a strong oxidation of photoexcited holes in the valence band could be responsible for the dye degradation [18]. 


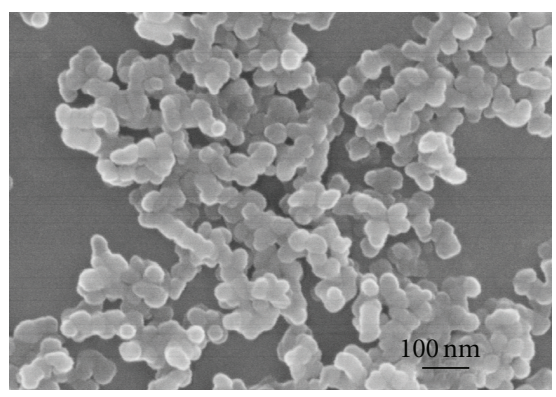

(a)

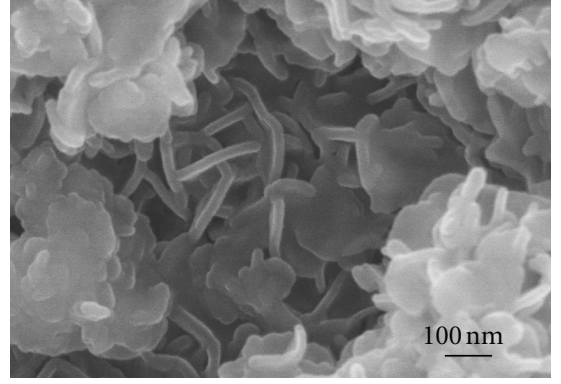

(b)

Figure 3: SEM images of (a) LDH and (b) FLDH.

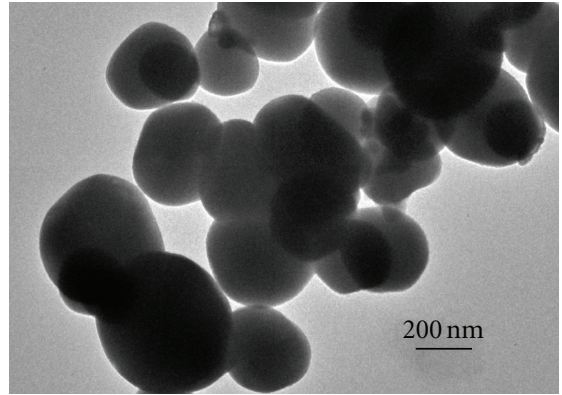

(a)

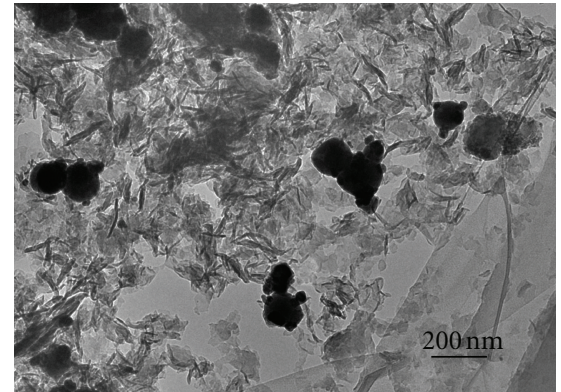

(b)

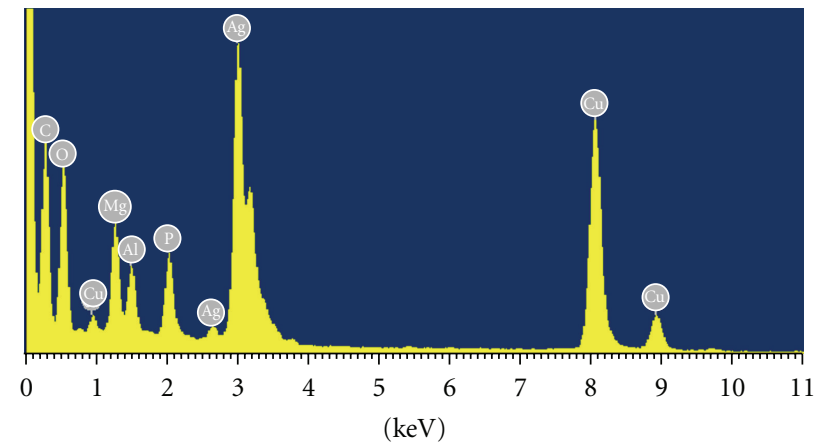

(c)

Figure 4: TEM images of $\mathrm{Ag}_{3} \mathrm{PO}_{4}$ (a) and $\mathrm{Ag}_{3} \mathrm{PO}_{4} / \mathrm{FLDH}-3$ (b), and EDS elemental microanalysis of $\mathrm{Ag}_{3} \mathrm{PO}_{4} / \mathrm{FLDH}_{-3}$ (c).

The photocatalytic activities in decomposing ARG are plotted in Figure 6, where $C_{0}$ and $C_{t}$ are the concentration of aqueous ARG in the starting aqueous $(50 \mathrm{mg} / \mathrm{L})$ and at time $t$, respectively. All of the samples showed efficient photocatalytic activities under visible light irradiation, indicating the potential of $\mathrm{Ag}_{3} \mathrm{PO}_{4}$ as a photofunctional material for waste water cleaning. It can be clearly seen that both of the $\mathrm{Ag}_{3} \mathrm{PO}_{4} / \mathrm{FLDH}$ photocatalysts exhibited higher photocatalytic activities for the ARG degradation reaction than bare $\mathrm{Ag}_{3} \mathrm{PO}_{4}$, especially $\mathrm{Ag}_{3} \mathrm{PO}_{4} / \mathrm{FLDH}-3$, the ARG dye can be completely degraded within 20 min under visible light irradiation.

The enhanced photocatalytic properties can be attributed to two main factors. First is the much smaller size and good dispersion of $\mathrm{Ag}_{3} \mathrm{PO}_{4}$ immobilized on the FLDH. It is well known that the light-generated charge carriers in small-sized semiconductor grains can efficiently transfer to the surface, which results in the decrease of the opportunities for recombination [28]. Meanwhile, for bare $\mathrm{Ag}_{3} \mathrm{PO}_{4}$, the by-products, black metallic Ag particles, would appear because of the photocorrosion during the photocatalytic process and attach themselves onto the surface of the $\mathrm{Ag}_{3} \mathrm{PO}_{4}$ catalyst, which would inevitably prevent visible light absorption and decrease its photocatalytic activity [23]. For the $\mathrm{Ag}_{3} \mathrm{PO}_{4} / \mathrm{FLDH}$ composites, the photocorrosion still existed, but the Ag particles resulted from the decomposition of much finer $\mathrm{Ag}_{3} \mathrm{PO}_{4}$ in the composite were also much smaller compared to that from the bare $\mathrm{Ag}_{3} \mathrm{PO}_{4}$. The finer $\mathrm{Ag}$ particles scattered less light and improved the light harvesting in the photocatalytic process. Moreover, a large part of Ag particles would deposit onto the surface of FLDH not coated by $\mathrm{Ag}_{3} \mathrm{PO}_{4}$ in the composites, which also further reduce the negative influence. Second is a higher adsorption capability for the composites compared with bare $\mathrm{Ag}_{3} \mathrm{PO}_{4}$. The photocatalytic degradation 


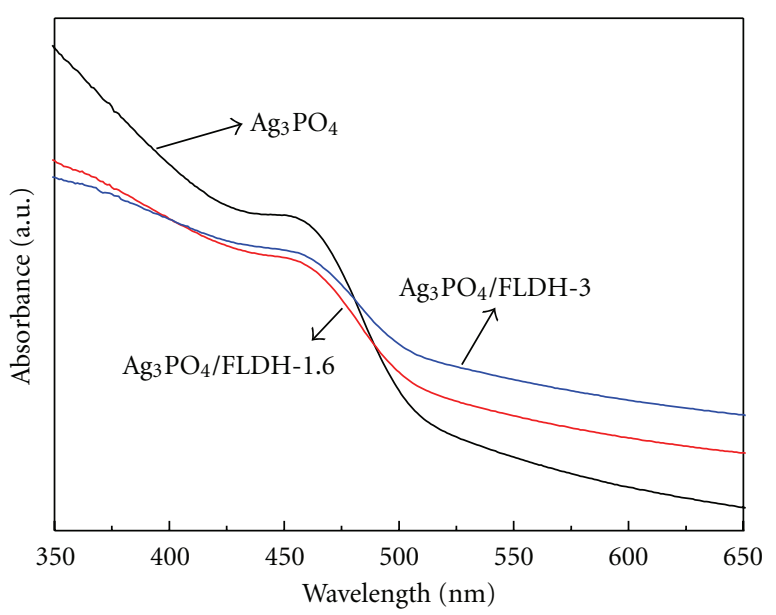

FIgure 5: UV-vis diffuse reflectance spectra of bare $\mathrm{Ag}_{3} \mathrm{PO}_{4}$ and $\mathrm{Ag}_{3} \mathrm{PO}_{4} / \mathrm{FLDH}$ composites.

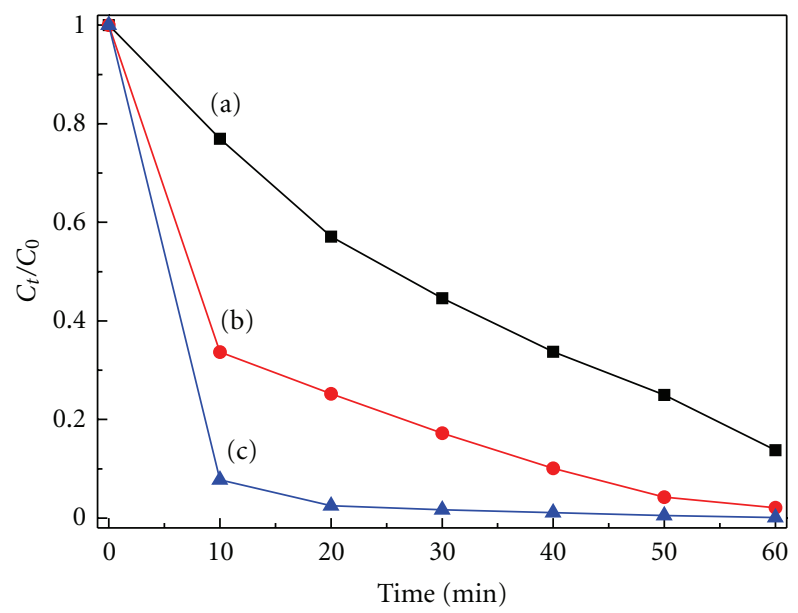

Figure 6: Photocatalytic activities of (a) $\mathrm{Ag}_{3} \mathrm{PO}_{4}$, (b) $\mathrm{Ag}_{3} \mathrm{PO}_{4} /$ FLDH-1.6, and (c) $\mathrm{Ag}_{3} \mathrm{PO}_{4} / \mathrm{FLDH}-3$ for ARG degradation under visible light irradiation.

of a pollutant must proceed at the surface of the catalyst after the reactant has been adsorbed on the surface, so the adsorption is considered to be the prestep for the consequent photocatalytic reaction [29]. According to the blank tests carried out like the way of photocatalytic degradation of ARG but without light irradiation, which are shown in Figure 7, it can be clearly seen that the adsorption of ARG on bare $\mathrm{Ag}_{3} \mathrm{PO}_{4}$ in the dark was negligible after $60 \mathrm{~min}$, however, the percentages of $\mathrm{ARG}$ removal with $\mathrm{Ag}_{3} \mathrm{PO}_{4} / \mathrm{FLDH}-1.6$ and $\mathrm{Ag}_{3} \mathrm{PO}_{4} / \mathrm{FLDH}-3$ were $\sim 35 \%$ and $55 \%$, respectively. These results indicate that the high adsorption capability is very crucial to the improvement of photocatalytic activation for the $\mathrm{Ag}_{3} \mathrm{PO}_{4} / \mathrm{FLDH}$ composites. For $\mathrm{Ag}_{3} \mathrm{PO}_{4} / \mathrm{FLDH}-3$, the excellent efficiency may be explained based on the smaller particle size, better dispersion of $\mathrm{Ag}_{3} \mathrm{PO}_{4}$ on the $\mathrm{FLDH}$, and higher adsorption capability with the amount of FLDH content.

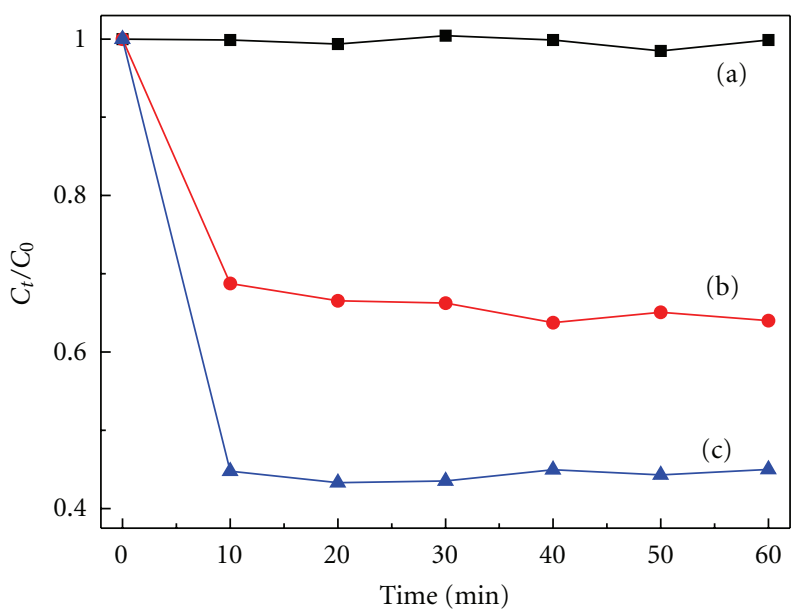

FIgURE 7: The adsorption capabilities of ARG on (a) $\mathrm{Ag}_{3} \mathrm{PO}_{4}$, (b) $\mathrm{Ag}_{3} \mathrm{PO}_{4} / \mathrm{FLDH}-1.6$ and (c) $\mathrm{Ag}_{3} \mathrm{PO}_{4} / \mathrm{FLDH}-3$ in the dark.

\section{Conclusions}

In summary, we synthesized the $\mathrm{Ag}_{3} \mathrm{PO}_{4} / \mathrm{FLDH}$ composites with fine $\mathrm{Ag}_{3} \mathrm{PO}_{4}$ crystalline grains through a wet chemical method. The $\mathrm{Ag}_{3} \mathrm{PO}_{4} / \mathrm{FLDH}$ composites, the $\mathrm{Ag}_{3} \mathrm{PO}_{4} /$ FLDH-3 in particular, exhibited much higher catalytic efficiency than bare $\mathrm{Ag}_{3} \mathrm{PO}_{4}$ for the degradation of $\mathrm{ARG}$ under visible light irradiation. The enhanced photocatalytic properties can be attributed to the combination of the smallersized and well-distributed $\mathrm{Ag}_{3} \mathrm{PO}_{4}$ immobilized on the FLDH and the strong adsorption of the dye on the FLDH.

\section{Acknowledgments}

This work was supported by National Key Technology R\&D Program (no. 2006BAA04B02-01) and Shanghai Leading Academic Discipline Project (B603).

\section{References}

[1] G. Li, D. Zhang, and J. C. Yu, "Ordered mesoporous $\mathrm{BiVO}_{4}$ through nanocasting: a superior visible light-driven photocatalyst," Chemistry of Materials, vol. 20, no. 12, pp. 3983-3992, 2008.

[2] C. An, S. Peng, and Y. Sun, "Facile synthesis of sunlight-driven AgCl: Ag plasmonic nanophotocatalyst," Advanced Materials, vol. 22, no. 23, pp. 2570-2574, 2010.

[3] Z. Liu, H. Bai, and D. Sun, "Facile fabrication of hierarchical porous $\mathrm{TiO}_{2}$ hollow microspheres with high photocatalytic activity for water purification," Applied Catalysis B, vol. 104, no. 3-4, pp. 234-238, 2011.

[4] S. Yuan, Y. Li, Q. Zhang, and H. Wang, "ZnO nanorods decorated calcined $\mathrm{Mg}$-Al layered double hydroxides as photocatalysts with a high adsorptive capacity," Colloids and Surfaces A, vol. 348, no. 1-3, pp. 76-81, 2009.

[5] Q. Zhang, W. Fan, and L. Gao, "Anatase $\mathrm{TiO}_{2}$ nanoparticles immobilized on $\mathrm{ZnO}$ tetrapods as a highly efficient and easily recyclable photocatalyst," Applied Catalysis B, vol. 76, no. 1-2, pp. 168-173, 2007. 
[6] M. L. Chen and W. C. Oh, "The improved photocatalytic properties of methylene blue for $\mathrm{V}_{2} \mathrm{O}_{3} / \mathrm{CNT} / \mathrm{TiO}_{2}$ composite under visible light," International Journal of Photoenergy, vol. 2010, Article ID 264831, 5 pages, 2010.

[7] K. Lv, Q. Xiang, and J. Yu, "Effect of calcination temperature on morphology and photocatalytic activity of anatase $\mathrm{TiO}_{2}$ nanosheets with exposed 001 facets," Applied Catalysis B, vol. 104, no. 3-4, pp. 275-281, 2011.

[8] G. Cao, Y. Li, Q. Zhang, and H. Wang, "Synthesis and characterization of $\mathrm{La}_{2} \mathrm{O}_{3} / \mathrm{TiO}_{2-x} \mathrm{~F}_{x}$ and the visible light photocatalytic oxidation of 4-chlorophenol," Journal of Hazardous Materials, vol. 178, no. 1-3, pp. 440-449, 2010.

[9] Y. Wang, C. Feng, M. Zhang, J. Yang, and Z. Zhang, "Visible light active $\mathrm{N}$-doped $\mathrm{TiO}_{2}$ prepared from different precursors: origin of the visible light absorption and photoactivity," Applied Catalysis B, vol. 104, no. 3-4, pp. 268-274, 2011.

[10] Q. Zhang and L. Gao, " $\mathrm{Ta}_{3} \mathrm{~N}_{5}$ nanoparticles with enhanced photocatalytic efficiency under visible light irradiation," Langmuir, vol. 20, no. 22, pp. 9821-9827, 2004.

[11] K. Maeda, K. Teramura, and Lu D. L., "Photocatalyst releasing hydrogen from water-enhancing catalytic performance holds promise for hydrogen production by water splitting in sunlight," Nature, vol. 440, no. 7082, p. 295, 2006.

[12] M. Yashima, H. Yamada, K. Maeda, and K. Domen, "Experimental visualization of covalent bonds and structural disorder in a gallium zinc oxynitride photocatalyst $\left(\mathrm{Ga}_{1-x} \mathrm{Zn}_{x}\right)$ $\left(\mathrm{N}_{1-x} \mathrm{O}_{x}\right)$ : origin of visible light absorption," Chemical Communications, vol. 46, no. 14, pp. 2379-2381, 2010.

[13] A. Kudo, K. Omori, and H. Kato, "A novel aqueous process for preparation of crystal form-controlled and highly crystalline $\mathrm{BiVO}_{4}$ powder from layered vanadates at room temperature and its photocatalytic and photophysical properties," Journal of the American Chemical Society, vol. 121, no. 49, pp. 1145911467, 1999.

[14] G. Xi and J. Ye, "Synthesis of bismuth vanadate nanoplates with exposed 001 facets and enhanced visible-light photocatalytic properties," Chemical Communications, vol. 46, no. 11, pp. 1893-1895, 2010.

[15] Z. Zhang, W. Wang, M. Shang, and W. Yin, "Low-temperature combustion synthesis of $\mathrm{Bi}_{2} \mathrm{WO}_{6}$ nanoparticles as a visiblelight-driven photocatalyst," Journal of Hazardous Materials, vol. 177, no. 1-3, pp. 1013-1018, 2010.

[16] M. Shang, W. Wang, S. Sun, L. Zhou, and L. Zhang, " $\mathrm{Bi}_{2} \mathrm{WO}_{6}$ nanocrystals with high photocatalytic activities under visible light," Journal of Physical Chemistry C, vol. 112, no. 28, pp. 10407-10411, 2008.

[17] S. Ouyang, Z. Li, Z. Ouyang, T. Yu, J. Ye, and Z. Zou, "Correlation of crystal structures, electronic structures, and photocatalytic properties in a series of Ag-based oxides: $\mathrm{AgAlO}_{2}$, $\mathrm{AgCrO}_{2}$, and $\mathrm{Ag}_{2} \mathrm{CrO}_{4}$," Journal of Physical Chemistry C, vol. 112, no. 8, pp. 3134-3141, 2008.

[18] Z. Yi, J. Ye, N. Kikugawa et al., "An orthophosphate semiconductor with photooxidation properties under visible-light irradiation," Nature Materials, vol. 9, no. 7, pp. 559-564, 2010.

[19] T. Hibino and W. Jones, "New approach to the delamination of layered double hydroxides," Journal of Materials Chemistry, vol. 11, no. 5, pp. 1321-1323, 2001.

[20] K. Klemkaite, A. Khinsky, and A. Kareiva, "Reconstitution effect of $\mathrm{Mg} / \mathrm{Ni} / \mathrm{Al}$ layered double hydroxide," Materials Letters, vol. 65, no. 2, pp. 388-391, 2011.

[21] Y. Zhi, Y. Li, Q. Zhang, and H. Wang, "ZnO nanoparticles immobilized on flaky layered double hydroxides as photocatalysts with enhanced adsorptivity for removal of acid red G," Langmuir, vol. 26, no. 19, pp. 15546-15553, 2010.
[22] W. T. Reichle, "Synthesis of anionic clay minerals (mixed metal hydroxides, hydrotalcite)," Solid State Ionics, vol. 22, no. 1, pp. 135-141, 1986.

[23] Y. Bi, S. Ouyang, J. Cao, and J. Ye, "Facile synthesis of rhombic dodecahedral $\mathrm{AgX} / \mathrm{Ag}_{3} \mathrm{PO}_{4}(\mathrm{X}=\mathrm{Cl}, \mathrm{Br}, \mathrm{I})$ heterocrystals with enhanced photocatalytic properties and stabilities," Physical Chemistry Chemical Physics, vol. 13, no. 21, pp. 10071-10075, 2011.

[24] F. Millange, R. I. Walton, and D. O’Hare, “Time-resolved in situ X-ray diffraction study of the liquid-phase reconstructitm of Mg-Al-carboaate hydrotalcite-like compounds," Journal of Materials Chemistry, vol. 10, no. 7, pp. 1713-1720, 2000.

[25] F. R. Costa, A. Leuteritz, U. Wagenknecht, D. Jehnichen, L. Häußler, and G. Heinrich, "Intercalation of Mg-Al layered double hydroxide by anionic surfactants: preparation and characterization," Applied Clay Science, vol. 38, no. 3-4, pp. 153-164, 2008.

[26] L. Wang, X. Xu, D. G. Evans, X. Duan, and D. Li, "Synthesis and selective IR absorption properties of iminodiacetic-acid intercalated MgAl-layered double hydroxide," Journal of Solid State Chemistry, vol. 183, no. 5, pp. 1114-1119, 2010.

[27] X. Ma, B. Lu, D. Li, R. Shi, C. Pan, and Y. Zhu, "Origin of photocatalytic activation of silver orthophosphate from firstprinciples," Journal of Physical Chemistry C, vol. 115, no. 11, pp. 4680-4687, 2011.

[28] L. Zhang, W. Wang, J. Yang et al., "Sonochemical synthesis of nanocrystallite $\mathrm{Bi}_{2} \mathrm{O}_{3}$ as a visible-light-driven photocatalyst," Applied Catalysis A, vol. 308, pp. 105-110, 2006.

[29] J. Liu, M. Dong, S. Zuo, and Y. Yu, "Solvothermal preparation of $\mathrm{TiO}_{2} /$ montmorillonite and photocatalytic activity," Applied Clay Science, vol. 43, no. 2, pp. 156-159, 2009. 


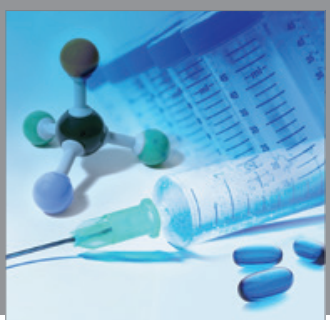

International Journal of

Medicinal Chemistry

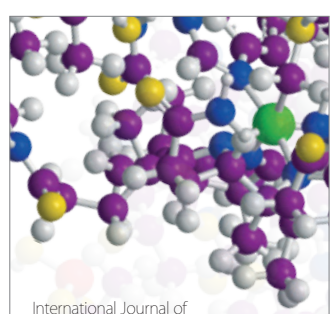

Carbohydrate Chemistry

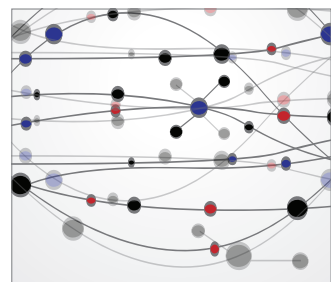

The Scientific World Journal
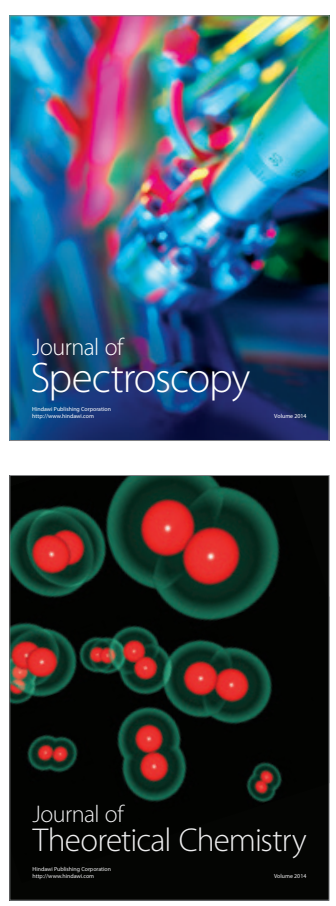
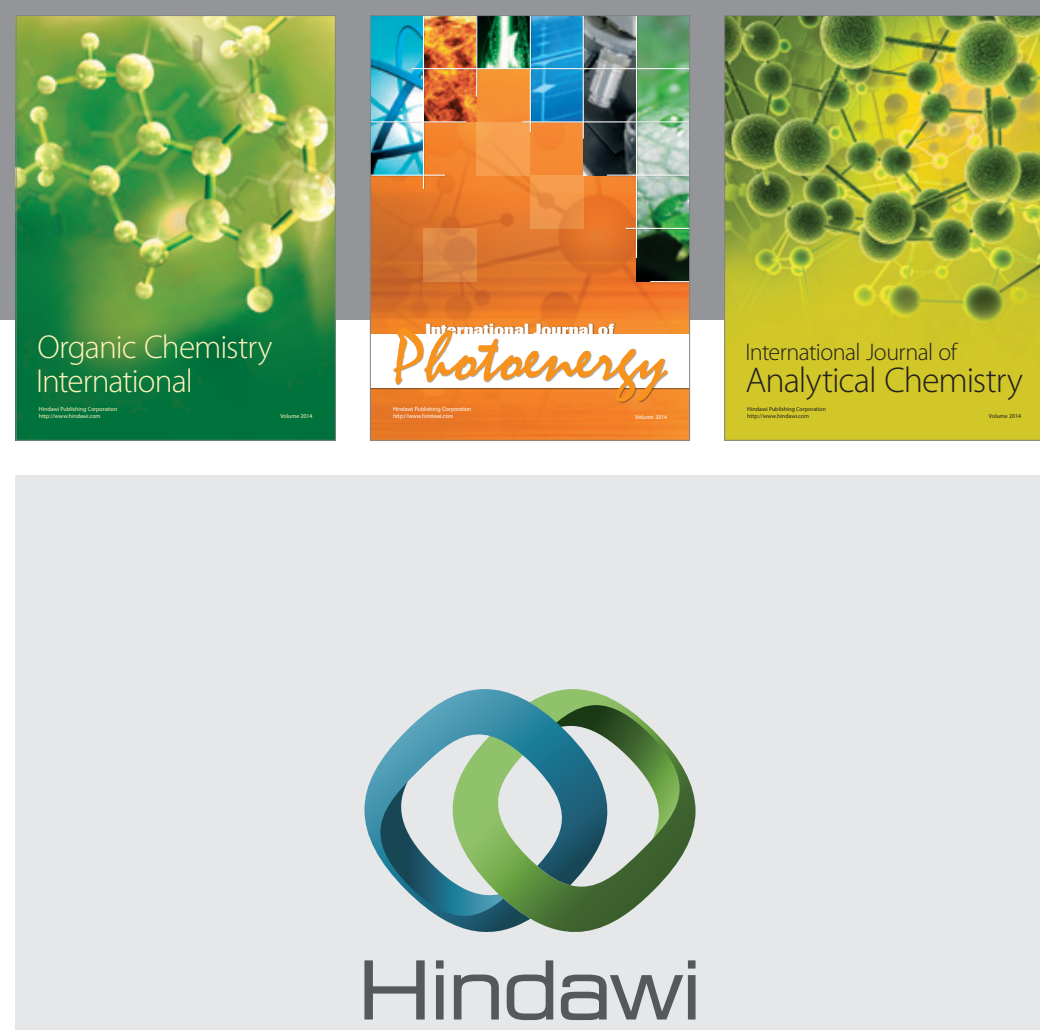

Submit your manuscripts at

http://www.hindawi.com
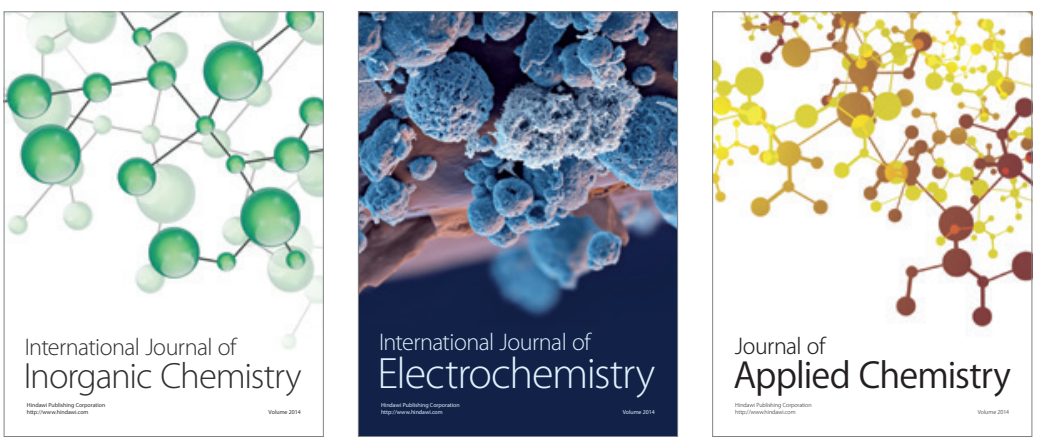

Journal of

Applied Chemistry
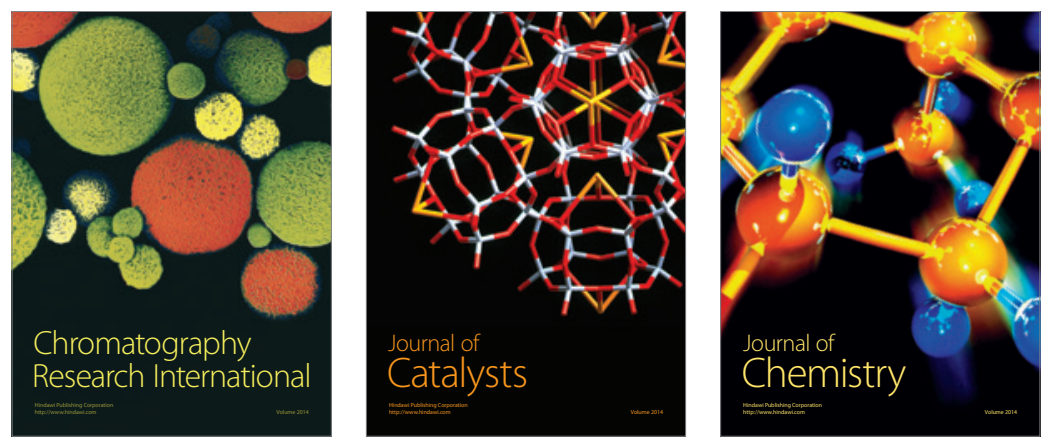
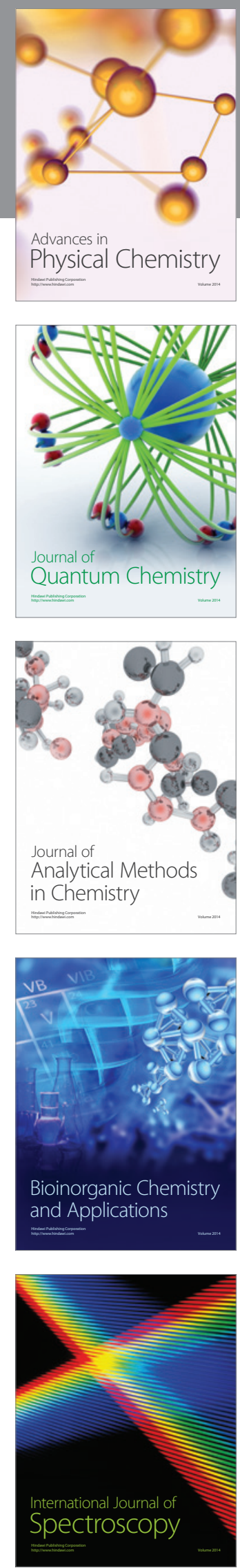